Martina Rauch

Antun Galović

Nenad Ferdelji

Saša Mudrinić

https://doi.org/10.21278/TOF.42Si102

ISSN 1333-1124

eISSN 1849-1391

\title{
LOCAL ENTROPY PRODUCTION OF THE PARALLEL FLOW AND COUNTERFLOW HEAT EXCHANGER
}

\begin{abstract}
Summary
The paper gives an analytical dimensionless analysis of the local entropy generation and its ratio with the local exchanged heat flow rate for parallel flow and counterflow heat exchangers. The end (side) of the heat exchanger, which is the inlet of the weaker stream, is, among other, proven to be relevant variable for those local values. Elaborated algorithm provides explicit connection between entropy generation and ratio of entropy generation to local exchanged heat flow rate in dependence on the relevant dimensionless variables $A / A_{0}$, $\pi_{2}=k A_{0} / C_{1}, \pi_{3}=C_{1} / C_{2}$ and $\pi_{T}=T_{1}^{\prime} / T_{2}^{\prime}$. Value $\pi_{2}$ vary between 1.0 and 4.0 , value $\pi_{3}$ amounts $0.0 ; 0.5$ and 1.0, while 0.5 and 2.0 were taken for value $\pi_{T}$. From obtained general equations for parallel flow and counterflow heat exchanger special cases for observed values were extracted, considering the cases where one of the streams condenses or evaporates. Given algorithm, aside the local amounts of the observed values, also gives overall amounts of the mentioned values. The results are presented by appropriate diagrams and additionally interpreted.
\end{abstract}

Key words: $\quad$ parallel flow and counterflow heat exchanger, local entropy generation, local rate of heat flow, dimensionless analysis

\section{Introduction}

Entropy generation (exergy destruction generation) in heat exchangers rests on two simultaneous irreversible processes: heat transfer between two streams with different temperatures, as well as on existence of pressure drop due to imposed resistance to flow. In many scientific papers, both recently published and published some time ago, and in many of the scientific books, a great number of researches covering the field of entropy (exergy) analysis of the heat exchangers can be found. Surely, [1] and [2], elaborating this problem in detail, are on the top of this list. Detailed analysis of impact of the both factors on entropy generation is given in [1], also giving the guidelines for obtaining heat exchanger operating regime at which minimum entropy (minimum exergy destruction) is generated. Specially elaborated is the case of so called balanced counterflow heat exchanger, where both streams 
have equal heat capacities. Many papers researching entropy production in individual heat exchangers have been written, like in $[3,4]$, where entropy production is calculated in a shell and tube heat exchanger, or in [5], where entropy analysis of a single air cooled heat exchanger is shown. An interesting entropy analysis of three different heat exchangers using nanofluid as a working fluid is given in [6]. Many recent papers determine optimum parameters of the heat exchanger operation using minimum entropy production criterion [79]. Authors in [10] suggest advanced approach for the minimization of entropy production, having design of optimum heat exchanger as a goal. Optimization of a cross-flow plate heat exchanger, aiming to minimize entropy production is also conducted in [11]. Entropy production in a heat exchanger is a result of heat transfer at final temperature differences between the streams and the pressure drop inside heat exchanger itself, so final optimum solution is obtained using Pareto fronts. Thermodynamic optimum parameters of the geothermal heat pump are also determined by minimization of entropy generation method in [12].

All of those papers deal mainly with overall entropy generation (exergy destruction), meaning that the object of analysis is the whole heat exchanger. No paper dealing with this problem on a local scale was found, when reviewing the recent literature, which was an additional argument for working on this paper. A clear illustration of entropy production on every part of heat exchanger area is gained upon analysis of the heat exchanger on a local level, and exactly that fact presents the novelty of this paper. This paper gives a full scale dimensionless mathematical model used for easy determination of both local and global entropy production, when different inlet and outlet temperatures of streams are at disposal. Dimensionless variables presented within this paper consist of heat properties of the streams, mass flow rates of the streams and flow regimes. The following mathematical model encompasses local entropy production of parallel flow and counterflow heat exchanger and a case when one of the streams changes it state of aggregation, i.e. if one of the streams condenses or evaporates.

\section{Elaboration of the mathematical model}

This elaboration covers parallel flow and counterflow heat exchanger, for which analytical overview of entropy production is given, generated only for heat transfer at final temperature differences of the streams. For that kind of heat exchangers it is easy to define the dependence of their temperatures on local heat exchanger area.

Initial equation for local entropy generation because of the heat transfer between the two streams at final temperature differences can be found in [1]

$$
\dot{S}_{\text {gen }}=k \int_{A=0}^{A} \frac{\left(T_{1}-T_{2}\right)^{2}}{T_{1} T_{2}} \mathrm{~d} A
$$

showing how entropy generation is directly proportional to temperature difference squared and inversely proportional to a product of their absolute (thermodynamic) values. Of course, result of the integral above depends on the type of the heat exchanger (parallel flow or counterflow). Furthermore, that result will also depend on the position of stream inlet. Temperature difference and absolute temperature amount of the fluid flowing through the heat exchanger are both changing and therefore heat exchangers are very appropriate for quantitative analysis in Eq. (1). 


\subsection{Weaker stream inlet at $A=0$}

\subsubsection{Parallel flow heat exchanger}

Final dimensionless form of the parallel flow heat exchanger local entropy production is shown by Eq. (2)

$$
\begin{aligned}
& \frac{\dot{S}_{\text {gen }}}{\dot{C}_{1}}=\ln \frac{1+\pi_{3} \pi_{T}+\left(\pi_{T}-1\right) \exp \left(-\pi_{2}\left(1+\pi_{3}\right) \frac{A}{A_{0}}\right)}{\pi_{T}\left(1+\pi_{3}\right)} \\
& +\frac{1}{\pi_{3}} \frac{1+\pi_{3} \pi_{T}-\pi_{3}\left(1-\pi_{T}\right) \exp \left(-\pi_{2}\left(1+\pi_{3}\right) \frac{A}{A_{0}}\right)}{\pi_{3}+1}
\end{aligned}
$$

where:

$\pi_{T}=\frac{T_{1}^{\prime}}{T_{2}^{\prime}}$

Eq. (2) describes local entropy production for every heat exchanger defined by values $\pi_{2}$ and $\pi_{3}$. Along those values, additional parameter for entropy production is evidently $\pi_{T}$, so local entropy generation is a function of four dimensionless variables, $\dot{S}_{\text {gen }} / \dot{C}_{1}=\mathrm{f}\left(\pi_{2}, \pi_{3}, \pi_{T}, A / A_{0}\right)$. These variables, except $A / A_{0}$, are mentioned as relevant and in [13-15].

For $A / A_{0}=0.0$, from Eq. (2), arises physically justified solution that $\dot{S}_{\text {gen }} / C_{1}=0$, and for $A / A_{0}=1.0$ overall entropy generation in observed heat exchanger is obtained.

$$
\begin{aligned}
& \frac{\dot{S}_{\text {gen }}}{\dot{C}_{1}}=\ln \frac{1+\pi_{3} \pi_{T}+\left(\pi_{T}-1\right) \exp \left(-\pi_{2}\left(1+\pi_{3}\right)\right)}{\pi_{T}\left(1+\pi_{3}\right)} \\
& +\frac{1}{\pi_{3}} \frac{1+\pi_{3} \pi_{T}-\pi_{3}\left(1-\pi_{T}\right) \exp \left(-\pi_{2}\left(1+\pi_{3}\right)\right)}{\pi_{3}+1}
\end{aligned}
$$

Again, Eq. (2) shows how entropy generation with raising of variable $\pi_{2}$ soars towards asymptotic value, gained if hypothetical case $\pi_{2} \rightarrow \infty$ is inserted into Eq. (2), so it is

$$
\underset{\substack{\lim _{2} \rightarrow \infty \\ C_{1}}}{\dot{S}_{\mathrm{gen}}}=\ln \frac{1+\pi_{3} \pi_{T}}{\pi_{T}\left(1+\pi_{3}\right)}+\frac{1}{\pi_{3}} \ln \frac{1+\pi_{3} \pi_{T}}{1+\pi_{3}}
$$

In a case of phase change of one of the streams (evaporation or condensation) $\pi_{3}$ equals 0 . By direct insertion of that value into Eq. (2), the second addend of the equation gives indefinite form $0 / 0$, and by application of L'Hospital's rule solution for local entropy generation for this case is gained.

$$
\frac{\dot{S}_{\text {gen }}}{\dot{C}_{1}}\left(\pi_{3}=0\right)=\ln \frac{1+\left(\pi_{T}-1\right) \exp \left(-\pi_{2} \frac{A}{A_{0}}\right)}{\pi_{T}}+\left(\pi_{T}-1\right)\left(1-\exp \left(-\pi_{2} \frac{A}{A_{0}}\right)\right)
$$


If $A / A_{0}=1.0$ is inserted into equation above, overall entropy generation in such heat exchanger is shown with following equation.

$$
\frac{\dot{S}_{\text {gen }}}{\dot{C}_{1}}\left(\pi_{3}=0\right)=\ln \frac{1+\left(\pi_{T}-1\right) \exp \left(-\pi_{2}\right)}{\pi_{T}}+\left(\pi_{T}-1\right)\left(1-\exp \left(-\pi_{2}\right)\right)
$$

Hypothetically, if $\pi_{2} \rightarrow \infty$ is presumed, then from equation above follows

$$
\underset{\substack{\dot{S}_{2} \rightarrow \infty \\ \dot{C}_{1}}}{\dot{\dot{m}}_{3}}\left(\pi_{3}=0\right)=\ln \frac{1}{\pi_{T}}+\pi_{T}-1
$$

Since entropy production in this model is observed as a consequence of the heat transfer between two streams with different temperatures, it is convenient also to show the dependence of local heat flow on the relevant dimensionless variables.

Dimensionless expression for local heat flow rate is shown by Eq. (8).

$$
\frac{\Phi\left(\frac{A}{A_{0}}\right)}{C_{1}\left(T_{1}^{\prime}-T_{2}^{\prime}\right)}=\frac{\Phi\left(\frac{A}{A_{0}}\right)}{\Phi_{\max }}=\frac{1-\exp \left(-\left(1+\pi_{3}\right) \pi_{2} \frac{A}{A_{0}}\right)}{1+\pi_{3}}
$$

For $A / A_{0}=1.0$ well known expression for efficiency $\left(\varepsilon_{\mathrm{i}}\right)$ of parallel flow heat exchanger is gained, which can also be found, extracted in another way, in [15-17].

$$
\frac{\Phi\left(\frac{A}{A_{0}}=1\right)}{C_{1}\left(T_{1}^{\prime}-T_{2}^{\prime}\right)}=\frac{\Phi\left(\frac{A}{A_{0}}=1\right)}{\Phi_{\max }}=\frac{1-\exp \left(-\left(1+\pi_{3}\right) \pi_{2}\right)}{1+\pi_{3}}=\pi_{1 \mathrm{i}}=\varepsilon_{\mathrm{i}}
$$

Convenient indicator of the ratio of local entropy generation to local heat flow rate is a result of a ratio between Eq. (2) and (8).

Inserting $\pi_{3}=0$ into Eq. (8), dimensionless expression for local heat flow rate is gained, for a case of phase change of one of the streams

$$
\frac{\Phi\left(\frac{A}{A_{0}}\right)}{C_{1}\left(T_{1}^{\prime}-T_{2}^{\prime}\right)}=\frac{\Phi\left(\frac{A}{A_{0}}\right)}{\Phi_{\max }}=1-\exp \left(-\pi_{2} \frac{A}{A_{0}}\right)
$$

and by inserting je $A / A_{0}=1.0$ into the same equation, known expression for energy efficiency of the condenser (evaporator) is gained

$$
\frac{\Phi\left(\frac{A}{A_{0}}=1\right)}{C_{1}\left(T_{1}^{\prime}-T_{2}^{\prime}\right)}=\frac{\Phi\left(\frac{A}{A_{0}}=1\right)}{\Phi_{\max }}=1-\exp \left(-\pi_{2}\right)=\pi_{1}=\varepsilon
$$

\subsubsection{Counterflow heat exchanger}

Final dimensionless form of the counterflow flow heat exchanger local entropy production is shown by Eq. (12). 


$$
\begin{aligned}
& \frac{\dot{S}_{\text {gen }}}{\dot{C}_{1}}=\frac{1}{\pi_{3}} \ln \frac{1-\pi_{3} \pi_{T} \exp \left(-\pi_{2}\left(1-\pi_{3}\right)\right)+\left(\pi_{T}-1\right) \pi_{3}}{1-\pi_{3} \pi_{T} \exp \left(-\pi_{2}\left(1-\pi_{3}\right)\right)+\left(\pi_{T}-1\right) \pi_{3} \exp \left(-\pi_{2}\left(1-\pi_{3}\right) \frac{A}{A_{0}}\right)} \\
& +\ln \frac{1-\pi_{3} \pi_{T} \exp \left(-\pi_{2}\left(1-\pi_{3}\right)\right)+\left(\pi_{T}-1\right) \exp \left(-\pi_{2}\left(1-\pi_{3}\right) \frac{A}{A_{0}}\right)}{\pi_{T}\left(1-\pi_{3} \exp \left(-\pi_{2}\left(1-\pi_{3}\right)\right)\right)}
\end{aligned}
$$

Eq. (12) gives for $A / A_{0}=0$ a zero entropy generation value, while for $A / A_{0}=1.0$ gives overall entropy generation in observed heat exchanger-

$$
\begin{aligned}
& \frac{\dot{S}_{\text {gen }}}{\dot{C}_{1}}=\frac{1}{\pi_{3}} \ln \frac{1-\pi_{3} \pi_{T} \exp \left(-\pi_{2}\left(1-\pi_{3}\right)\right)+\left(\pi_{T}-1\right) \pi_{3}}{1-\exp \left(-\pi_{2}\left(1-\pi_{3}\right)\right)\left(\pi_{3} \pi_{T}+1-\pi_{T}\right)} \\
& +\ln \frac{1-\exp \left(-\pi_{2}\left(1-\pi_{3}\right)\right)\left(\pi_{3} \pi_{T}+1-\pi_{T}\right)}{\pi_{T}\left(1-\pi_{3} \pi_{T} \exp \left(-\pi_{2}\left(1-\pi_{3}\right)\right)\right)}
\end{aligned}
$$

For hypothetic case $\pi_{2} \rightarrow \infty$ equation above takes form

$$
\frac{\dot{S}_{\mathrm{gen}}}{C_{1}}=\ln \frac{\left[1+\left(\pi_{T}-1\right) \pi_{3}\right] \frac{1}{\pi_{3}}}{\pi_{T}}
$$

From Eq. (13) a solution of the case where one of the streams passes through the phase change can be obtained. Solution from Eq. (13), with fulfilled condition $\pi_{3}=0$, is identical to a solution given from Eq. (5) and overall entropy generation is obtained by resolving Eq. (6). It is important to note that Eq. (5) results with local entropy generation only in a case, as mentioned, when weaker stream enters the heat exchanger at $A=0$.

For hypothetic case $\pi_{2} \rightarrow \infty$ Eq. (15) is gained.

$$
\underset{\substack{\pi_{2} \rightarrow \infty \\ \dot{C}_{1}}}{\dot{S}_{\text {en }}}\left(\pi_{3}=0\right)=\frac{\pi_{T}^{2}-\pi_{T}+1}{\pi_{T}}
$$

Expression for observed counterflow heat exchanger, showing the dependence of heat flow rate on the local variable $A / A_{0}$ is shown by Eq. (16).

$$
\frac{\Phi\left(\frac{A}{A_{0}}\right)}{C_{1}\left(T_{1}^{\prime}-T_{2}^{\prime}\right)}=\frac{\Phi\left(\frac{A}{A_{0}}\right)}{\Phi_{\max }}=\frac{1-\exp \left(-\left(1-\pi_{3}\right) \pi_{2} \frac{A}{A_{0}}\right)}{1-\pi_{3} \exp \left(-\left(1-\pi_{3}\right) \pi_{2}\right)}
$$

Known function for counterflow heat exchanger efficiency is obtained from equation above, for $A / A_{0}=1.0$.

$$
\frac{\Phi\left(\frac{A}{A_{0}}=1\right)}{C_{1}\left(T_{1}^{\prime}-T_{2}^{\prime}\right)}=\frac{\Phi\left(\frac{A}{A_{0}}=1\right)}{\Phi_{\max }}=\frac{1-\exp \left(-\left(1-\pi_{3}\right) \pi_{2}\right)}{1-\pi_{3} \exp \left(-\left(1-\pi_{3}\right) \pi_{2}\right)}=\pi_{1 \mathrm{p}}=\varepsilon_{\mathrm{p}}
$$




\subsection{Weaker stream inlet $A=A_{0}$}

\subsubsection{Parallel flow heat exchanger}

Dimensionless form of the parallel flow heat exchanger local entropy production is shown by Eq. (18).

$$
\begin{aligned}
\frac{\dot{S}_{\mathrm{gen}}}{\dot{C}_{1}}= & \frac{1}{\pi_{3}} \ln \frac{\left(\pi_{T}-1\right) \pi_{3}-\left(\pi_{T} \pi_{3}+1\right) \exp \left(\pi_{2}\left(1+\pi_{3}\right)\right)}{\left(\pi_{T}-1\right) \pi_{3} \exp \left(\pi_{2}\left(1+\pi_{3}\right) \frac{A}{A_{0}}\right)-\left(\pi_{T} \pi_{3}+1\right) \exp \left(\pi_{2}\left(1+\pi_{3}\right)\right)} \\
& +\ln \frac{\left(\pi_{T} \pi_{3}+1\right) \exp \left(\pi_{2}\left(1+\pi_{3}\right)\right)+\pi_{T}-1}{\left(\pi_{T} \pi_{3}+1\right) \exp \left(\pi_{2}\left(1+\pi_{3}\right)\right)+\left(\pi_{T}-1\right) \pi_{3} \exp \left(\pi_{2}\left(1+\pi_{3}\right) \frac{A}{A_{0}}\right)}
\end{aligned}
$$

If $A / A_{0}=0.0$ is inserted into equation above, zero value of entropy generation is the result and for $A / A_{0}=1.0$ the result is overall entropy generation and equation is gained, equivalent to Eq. (3). In other words, in context of overall entropy generation, it is irrelevant at which side of the heat exchanger weaker stream enters. But, if Eq. (18) and (2) for calculation of local entropy generation are compared, it is evident that side of the streams inlet in the parallel flow heat exchanger has a great significance.

From equation above, analog to a procedure in 2.1.1, it is easy to obtain the expression for local entropy generation for a case when one of the streams changes its state of aggregation.

$$
\frac{\dot{S}_{\text {gen }}}{\dot{C}_{1}}\left(\pi_{3}=0\right)=\ln \frac{1+\left(\pi_{T}-1\right) \exp \left(-\pi_{2}\right)}{1+\left(\pi_{T}-1\right) \exp \left(\pi_{2}\left(\frac{A}{A_{0}}-1\right)\right)}+\left(\pi_{T}-1\right) \exp \left(-\pi_{2}\right)\left(\exp \left(\pi_{2} \frac{A}{A_{0}}\right)-1\right)
$$

If $A / A_{0}=1.0$ is inserted into Eq. (19), expression identical to expression (6) is gained, meaning that overall entropy generation in a condenser or evaporator is independent of the side of weaker stream inlet to a heat exchanger. However, in context of local entropy generation, according to Eq. (19) and (5), side of the parallel flow heat exchanger where weaker stream enters has a great significance.

Locally exchanged heat flow rate is shown by Eq. (20)

$$
\frac{\Phi\left(\frac{A}{A_{0}}\right)}{C_{1}\left(T_{1}^{\prime}-T_{2}^{\prime}\right)}=\frac{\Phi\left(\frac{A}{A_{0}}\right)}{\Phi_{\max }}=\frac{1}{\left(1+\pi_{3}\right) \exp \left(\left(1+\pi_{3}\right) \pi_{2}\right)}\left(\exp \left(\pi_{2}\left(1+\pi_{3}\right) \frac{A}{A_{0}}\right)-1\right)
$$

from which for $A / A_{0}=1.0$ expression shown in Eq. (9) is gained, and for $\pi_{3}=0.0$ expression above gives

$$
\frac{\Phi\left(\frac{A}{A_{0}}\right)}{C_{1}\left(T_{1}^{\prime}-T_{2}^{\prime}\right)}=\frac{\Phi\left(\frac{A}{A_{0}}\right)}{\Phi_{\max }}=\frac{1}{\exp \left(\pi_{2}\right)}\left(\exp \left(\pi_{2} \frac{A}{A_{0}}\right)-1\right)
$$

With $A / A_{0}=1.0$ expression identical to expression (11) is gained. 


\subsubsection{Counterflow heat exchanger}

An expression for local entropy generation in counterflow heat exchanger is shown by following equation.

$$
\begin{aligned}
& \frac{\dot{S}_{\text {gen }}}{\dot{C}_{1}}=\frac{1}{\pi_{3}} \ln \frac{1-\pi_{3} \pi_{T} \exp \left(-\pi_{2}\left(1-\pi_{3}\right)\right)+\left(\pi_{T}-1\right) \pi_{3} \exp \left(-\pi_{2}\left(1-\pi_{3}\right)\right) \cdot \exp \left(-\pi_{2}\left(\pi_{3}-1\right) \frac{A}{A_{0}}\right)}{1-\exp \left(-\pi_{2}\left(1-\pi_{3}\right)\right)\left(\pi_{T}-\pi_{3} \pi_{T}-1\right)} \\
& +\ln \frac{1-\exp \left(-\pi_{2}\left(1-\pi_{3}\right)\right)\left(\pi_{T}-\pi_{3} \pi_{T}-1\right)}{1-\pi_{3} \pi_{T} \exp \left(-\pi_{2}\left(1-\pi_{3}\right)\right)+\left(\pi_{T}-1\right) \exp \left(-\pi_{2}\left(1-\pi_{3}\right)\right) \cdot \exp \left(-\pi_{2}\left(\pi_{3}-1\right) \frac{A}{A_{0}}\right)}
\end{aligned}
$$

It is obvious, when comparing Eq. (22) and (12), how direction of fluid flow has a significant effect on entropy generation. For $A / A_{0}=0$ using equation above $\dot{S}_{\text {gen }} / \dot{C}_{1}=0$ is gained, and for $A / A_{0}=1.0$ overall entropy generation is obtained according to expression given in Eq. (13).

Eq. (22) also produces indeterminate form for a case with phase changes, where $\pi_{3}=0$. Solution is gained when applying L'Hospital's rule. Solution identical to the one is given by Eq. (19).

Expression for dimensionless heat flow rate is shown in following equation

$$
\frac{\Phi\left(\frac{A}{A_{0}}\right)}{C_{1}\left(T_{1}^{\prime}-T_{2}^{\prime}\right)}=\frac{\Phi\left(\frac{A}{A_{0}}\right)}{\Phi_{\max }}=\frac{\exp \left(-\pi_{2}\left(1-\pi_{3}\right)\right)}{1-\pi_{3} \exp \left(-\pi_{2}\left(1-\pi_{3}\right)\right)}\left(\frac{1}{\exp \left(-\pi_{2}\left(1-\pi_{3}\right) \frac{A}{A_{0}}\right)}-1\right)
$$

For $A / A_{0}=1.0$ identical expression from Eq. (17) is given.

\section{Overview and interpretations of the calculation results}

3.1 Cases in which weaker stream enters at $A=0$
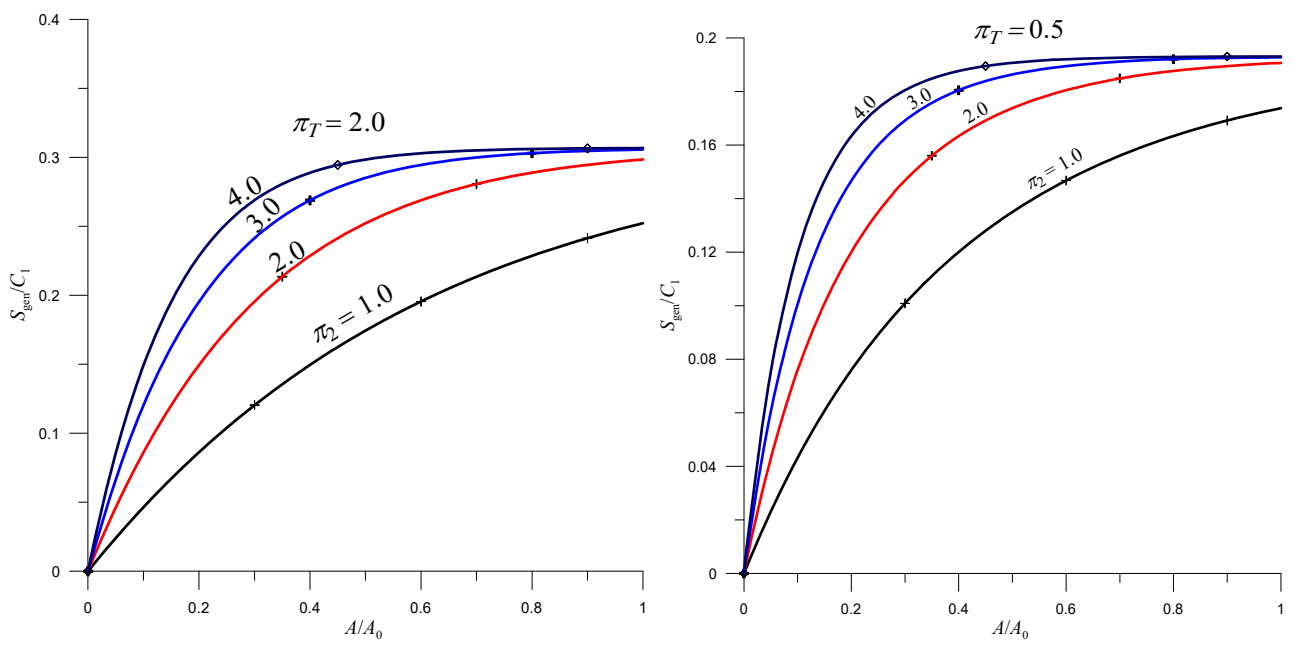

Fig. 1 Local entropy generation of the condenser $\left(\pi_{T}=0.5\right)$ and evaporator $\left(\pi_{T}=2.0\right)$ 
M. Rauch, A. Galović,

N. Ferdelji, S. Mudrinić
Local Entropy Production of the Parallel Flow and Counterflow Heat Exchanger
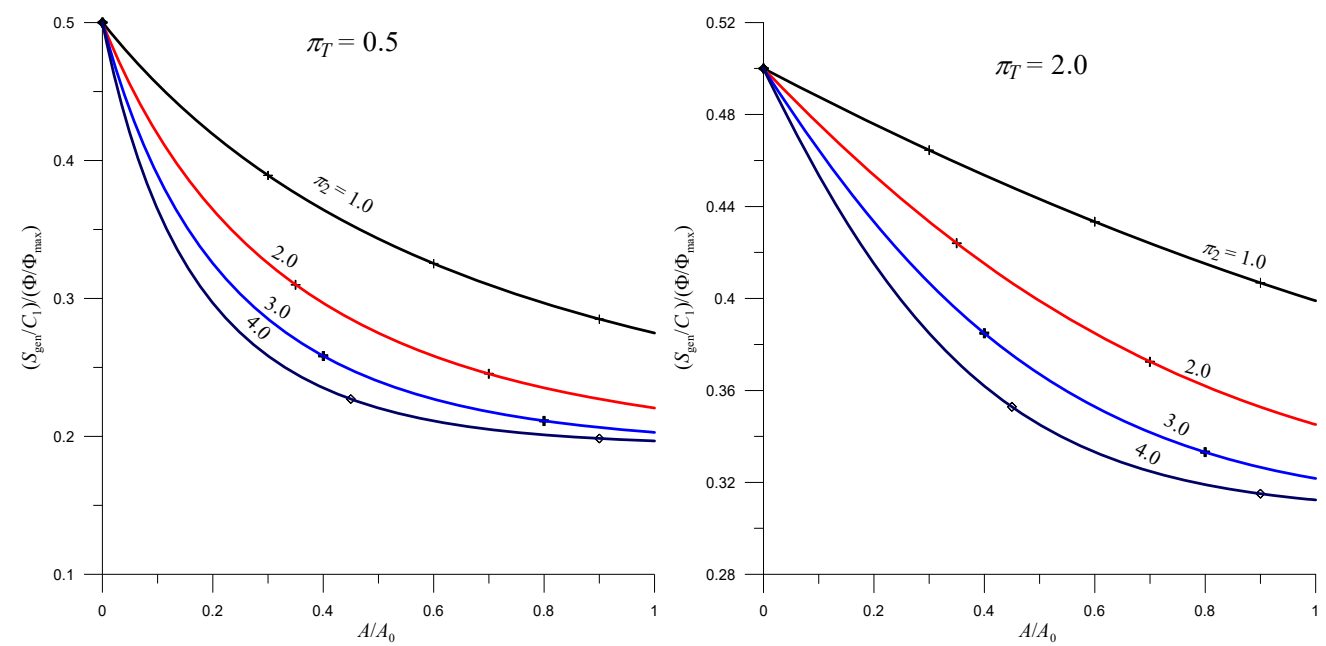

Fig. 2 Ratio of local entropy generation to local heat flow rate in condenser $\left(\pi_{T}=0.5\right)$ and in evaporator $\left(\pi_{T}=2.0\right)$
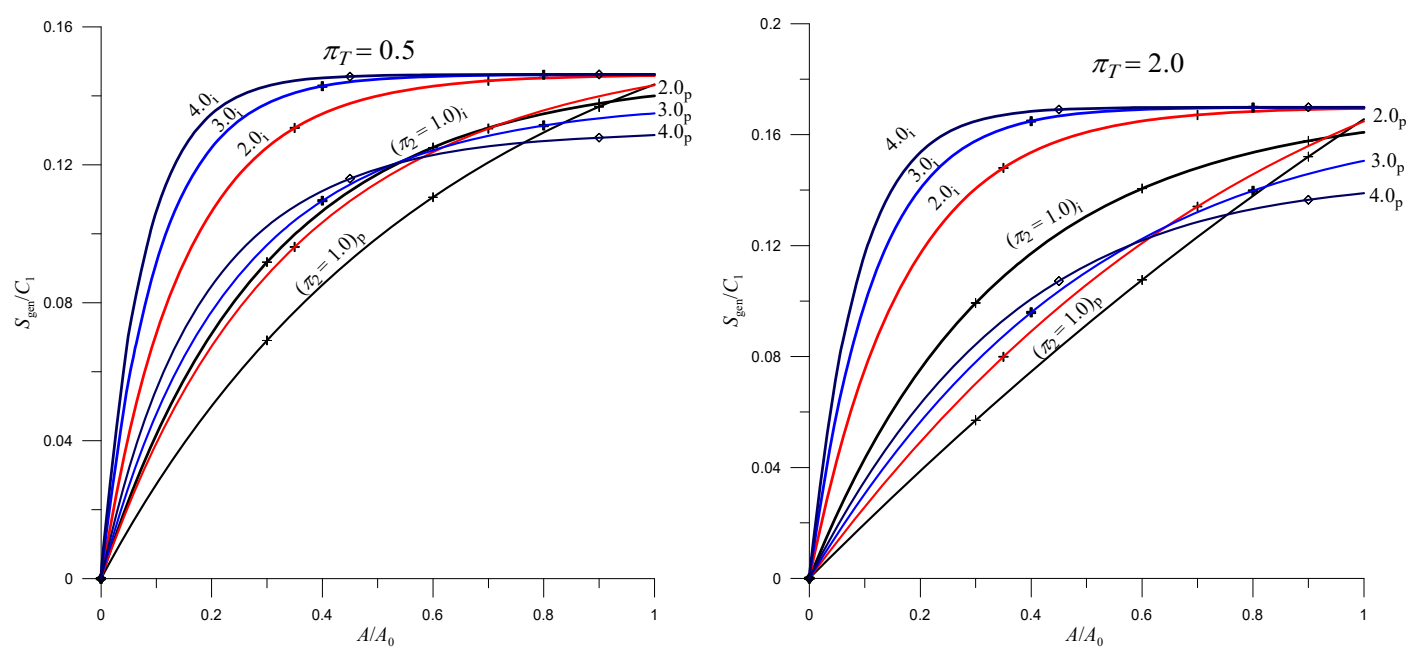

Fig. 3 Local entropy generation of the parallel flow (i) and counterflow (p) heat exchanger for $\pi_{3}=0.5$, and $\pi_{T}=0.5$ and 2.0
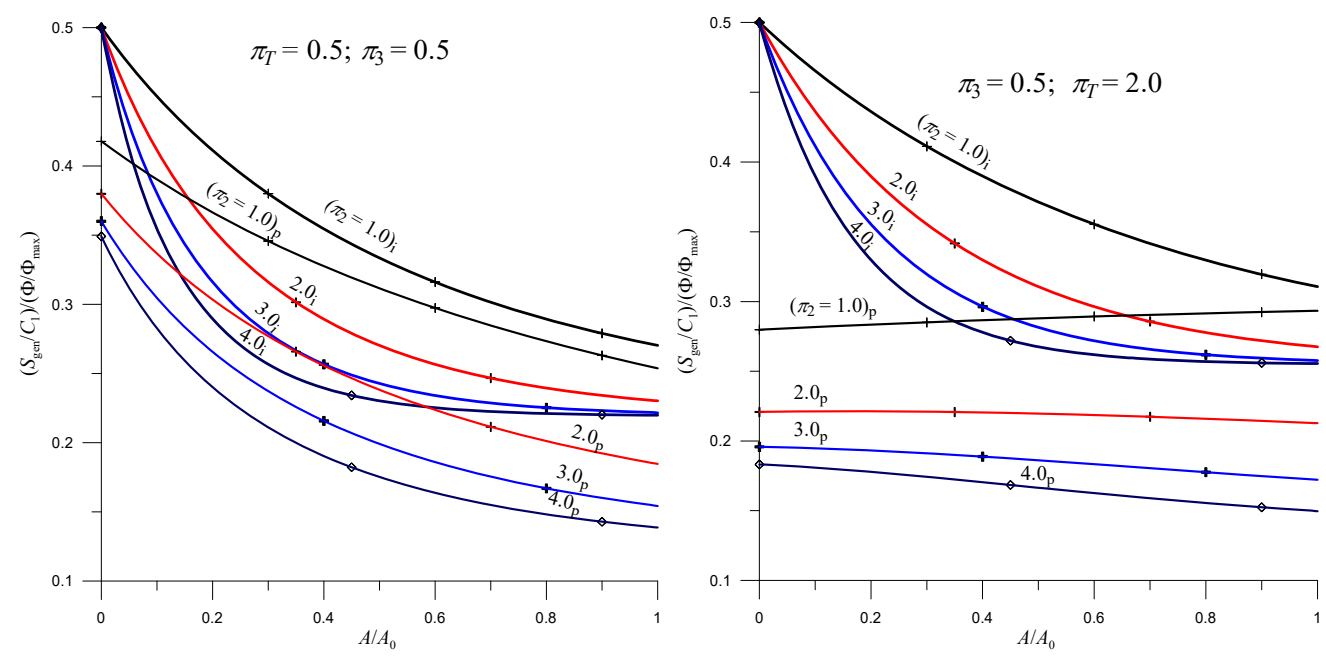

Fig. 4 Ratio of local entropy generation to local heat flow rate of the parallel flow (i) and counterflow (p) heat exchanger for $\pi_{3}=0.5$, and $\pi_{T}=0.5$ and 2.0 
Fig. 1 shows that value of the local entropy generation continuously rises along with the rise of variable $A / A_{0}$, but also with the rise of value $\pi_{2}$. For $A / A_{0}=1.0$, overall entropy generation for a certain condenser or evaporator is gained, defined by Eq. (6). Furthermore, with growth of $\pi_{2}$, local entropy generation practically reaches its asymptotic value, given in Eq. (7), by which that value amounts 0.193 for $\pi_{T}=0.5$ and 0.3069 for $\pi_{T}=2.0$. It is also concluded that entropy generation is higher for $\pi_{T}=2.0$ in relation to $\pi_{T}=0.5$.

Fig. 2 makes clear the fact that ratio of entropy generation to dimensionless heat flow rate declines with the increase of value $A / A_{0}$, as well as with the increase of value $\pi_{2}$. For $\pi_{T}=0.5$ and 2.0 related asymptotic values amount 0.1931 and 0.3069 and are practically achieved for both cases for $\pi_{2}=4.0$.

Diagram in Fig. 3 shows entropy generation of parallel flow and counterflow heat exchanger for the same ratio $\pi_{T}=0.5$ and 2.0 with $\pi_{3}=0.5$. Here type of the heat exchanger obviously has a significant effect on local entropy generation and it is also clear how for both heat exchanger types entropy generation rises along with the increase of variable $A / A_{0}$. While for parallel flow heat exchanger local entropy generation increases with the increase of $\pi_{2}$, for counterflow heat exchanger it first increases and then it decreases. Furthermore, it can be noticed how entropy generation is, for the same $\pi_{2}$ and $A / A_{0}$, significantly higher in parallel flow then in counterflow heat exchanger, and that difference increases with the increase of variables $\pi_{2}$ and $A / A_{0}$. For $A / A_{0}=1.0$ overall entropy generations of the concerned heat exchangers are gained, and they are evidently increased with the increase of $\pi_{2}$ in parallel flow heat exchanger and decreased in counterflow heat exchanger.

Results on Fig. 4 show that for both cases with parallel flow heat exchanger, $\pi_{T}=0.5$ and 2.0, the ratio of local entropy generation to local heat flow rate decreases continuously from value 0.5 and the drop soars to its asymptotic value. On the other hand this ratio for counterflow heat exchanger is always lower when compared with the one for parallel flow heat exchanger, which means that, by that criterion, counterflow heat exchanger is better. That ratio is emphasized at higher $\pi_{2}$ values. Ratio $A / A_{0}$ can be seen for which there is a minimum difference between calculated values of ratios for both types of heat exchangers for given $\pi_{T}$ and $\pi_{2}$.

3.2 Cases in which weaker stream enters at $A=A_{0}$

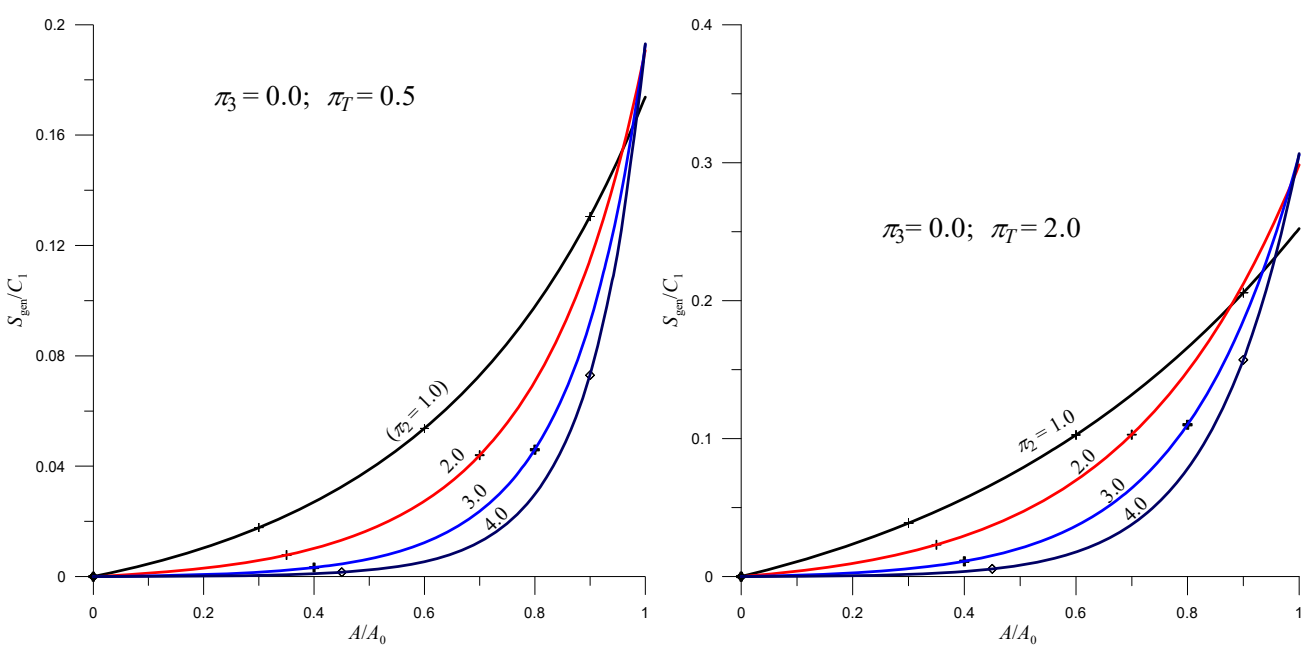

Fig. 5 Local entropy generation of the condenser $\left(\pi_{T}=0.5\right)$ and evaporator $\left(\pi_{T}=2.0\right)$ 
M. Rauch, A. Galović,

N. Ferdelji, S. Mudrinić
Local Entropy Production of the Parallel Flow and Counterflow Heat Exchanger
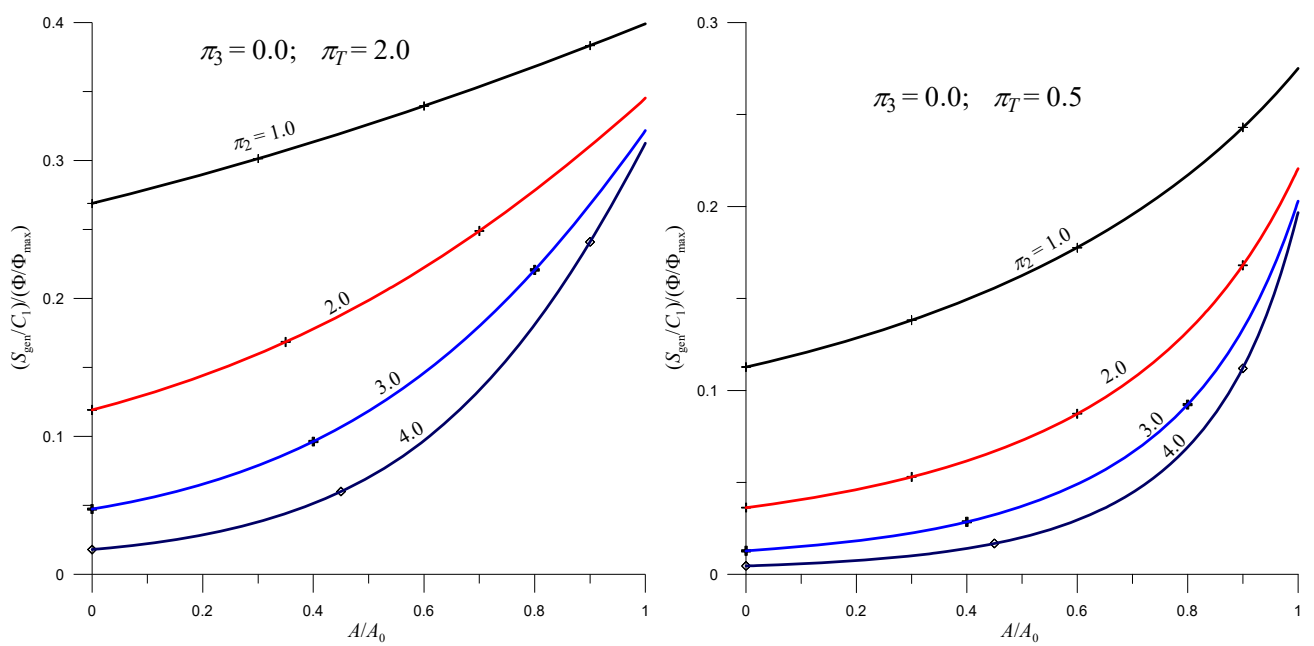

Fig. 6 Ratio of local entropy generation to local exchanged heat flow rate in condenser $\left(\pi_{T}=0.5\right)$ and in evaporator $\left(\pi_{T}=2.0\right)$
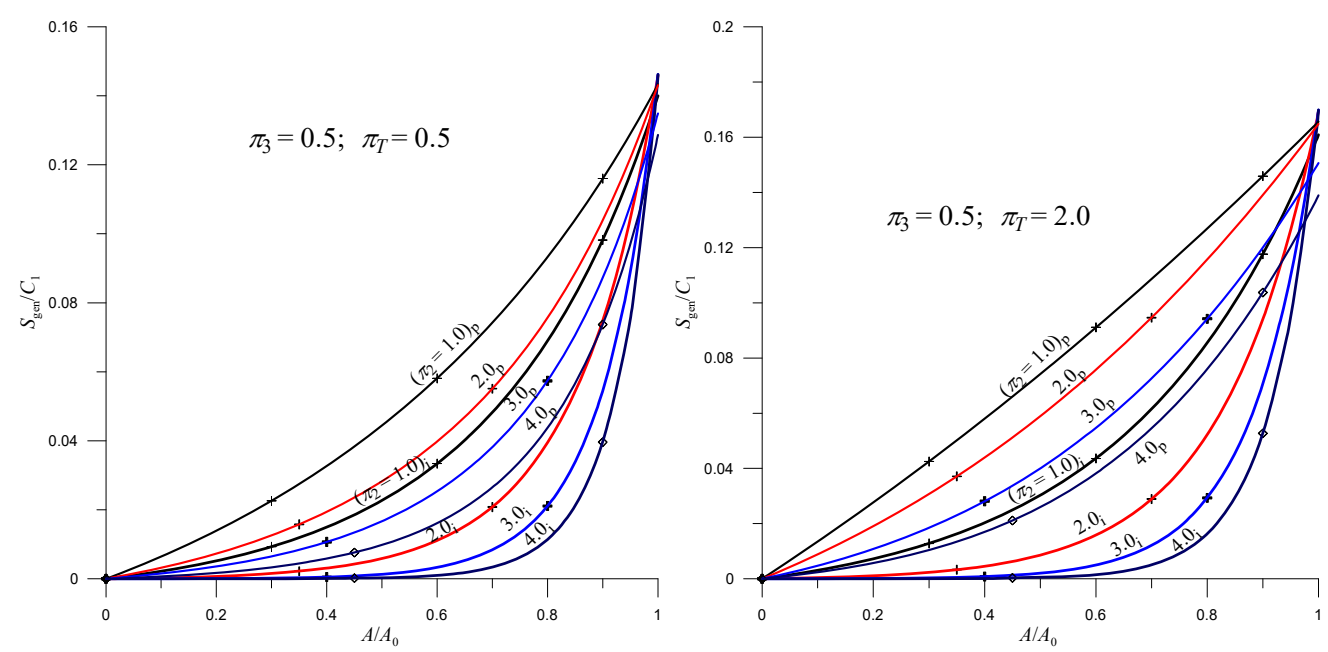

Fig. 7 Local entropy generation of the parallel flow (i) and counterflow (p) heat exchanger for $\pi_{3}=0.5$ and $\pi_{T}=0.5$ and 2.0
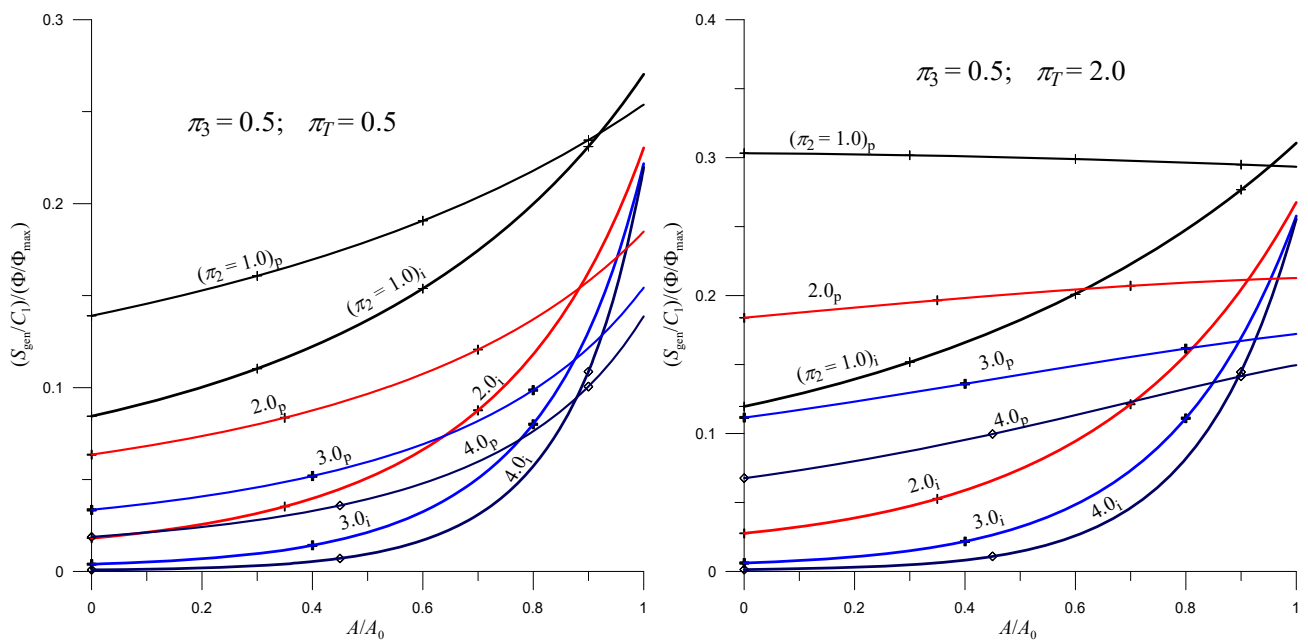

Fig. 8 Ratio of local entropy generation to local heat flow rate of the parallel flow (i) and counterflow (p) heat exchanger for $\pi_{3}=0.5$ and $\pi_{T}=0.5$ and 2.0 
Diagrams in Fig. 5 show entropy generation in condenser and evaporator. Diagrams clearly display continued increase of local entropy with the increase of variable $A / A_{0}$ and decrease of value $\pi_{2}$. For $A / A_{0}=1.0$ overall entropy generation of the condenser and evaporator is gained, which evidently rises along with the rise of value $\pi_{2}$.

Diagrams in Fig. 6 show the ratio of entropy generation to local exchanged heat flow rate, indicating that this ratio continuously increases with the increase of $A / A_{0}$, but drops with the increase of value $\pi_{2}$.

Diagrams in Fig. 7 show local entropy production of counterflow and parallel flow heat exchanger. When comparing the results from Fig. 3 with the results given in Fig. 7 it is evident that here again the side of the weaker stream entry has a great effect on the amount of local entropy generation. For the case presented local entropy generation in counterflow heat exchanger is, on a big part of the heat exchanger area, higher than in parallel flow heat exchanger, but overall entropy generation is higher in parallel flow than in counterflow heat exchanger. Differences between values of local entropy generations for these two heat exchangers rise with the rise of $\pi_{2}$, get equalized near the end of the heat exchanger and then entropy generation of the parallel flow heat exchanger prevails.

Trend of ratio of local entropy generation to local heat flow rate for observed heat exchangers is displayed in Fig. 8. When comparing the results in Fig. 4 it is concluded that here again the side of the weaker stream entry has a great effect on the amount of local entropy generation. While in Fig. 4 the ratio over whole interval $0 \leq A / A_{0} \leq 1.0$ was smaller for counterflow heat exchanger, following diagrams show that this ratio is smaller over a larger interval for parallel flow than it is for counterflow heat exchanger. Ratios come to equality as they near the end of heat exchanger area where the weaker stream enters. Counterflow heat exchanger then shows lower ratio values, as well as lower overall value of that ratio.

From conducted analysis arises the fact that the side of the heat exchanger through which stronger or weaker stream enters has no effect on overall entropy generation in heat exchanger types. That overall entropy generation is in many of the scientific papers, [18 - 25], obtained by use of parameters $\pi_{2}, \pi_{3}$ and $\pi_{T}$.

\section{Conclusion}

In this paper algorithm for calculating local entropy generation has encompassed all of the relevant dimensionless parameters which explicitly qualitative determine the local entropy generation in parallel flow and counterflow heat exchanger. Entropy generation in a heat exchanger showed in this paper is only a consequence of heat transfer between two streams with different temperatures. Entropy generation is normed with total heat capacity of the weaker stream and derived algorithm shows that the value of local entropy generation significantly depends on the fact on which side of the heat exchanger weaker stream enters. Cases when weaker stream enters at $A=0$ and at $A=A_{0}$ are elaborated, both for parallel flow and counterflow heat exchanger. Obtained expressions had shown that type of the heat exchanger has a significant effect on the amount of the local entropy generation. From these gained expressions for parallel flow and counterflow heat exchanger it was possible also to obtain the expressions for a case when one of the streams changes it state of aggregation, i.e. if one of the streams condenses or evaporates. But for overall entropy generation, mainly analyzed in former and more recent scientific papers, that fact becomes irrelevant. Mathematical model presented in the paper is tested according to many (individual) data from scientific references dealing with entropy generation in given operating regimes of certain heat exchangers and the result were satisfying. 
M. Rauch, A. Galović,

N. Ferdelji, S. Mudrinić
Local Entropy Production of the Parallel Flow and Counterflow Heat Exchanger

\section{Nomenclature}

\begin{tabular}{cll}
$\Phi$ & Heat flow rate & $\mathrm{W}$ \\
$\Phi\left(\frac{A}{A_{0}}\right)$ & Dimensionless local heat flow rate & - \\
\hline$C_{1}\left(T_{1}^{\prime}-T_{2}^{\prime}\right)$ & & \\
$A / A_{0}$ & Dimensionless heat exchanger area & - \\
$C_{1}$ & Heat capacity of weaker stream & $\mathrm{W} / \mathrm{K}$ \\
$C_{2}$ & Heat capacity of stronger stream & $\mathrm{W} / \mathrm{K}$ \\
$k$ & Overall heat transfer coefficient & $\mathrm{W} /\left(\mathrm{m}^{2} \mathrm{~K}\right)$ \\
$\dot{S}_{\text {gen }}$ & Local entropy generation & $\mathrm{W} / \mathrm{K}$ \\
$\dot{S}_{\text {gen }}$ & Dimensionless number presenting local entropy & - \\
$\dot{C}_{1}$ & generation & $\mathrm{K}$ \\
$T_{1}^{\prime}$ & Inlet temperature of weaker stream & $\mathrm{K}$ \\
$T_{2}^{\prime}$ & Inlet temperature of stronger stream & - \\
$\pi_{1}(\varepsilon)$ & Effectiveness of the heat exchanger & - \\
$\pi_{2}$ & $\frac{k A_{0}}{C_{1}} ;$ NTU (Number of Transfer Units) & - \\
$\pi_{3}$ & $\frac{C_{1}}{C_{2}} ;$ dimensionless number presenting heat & \\
& capacity ratio & \\
$\pi_{T}$ & Dimensionless number presenting ratio of inlet & \\
& stronger stream & \\
\hline
\end{tabular}

\section{REFERENCES}

[1] Bejan, A.: Entropy Generation Minimization, CRC Press, Boca Raton, 2000.

[2] Shah, R, K., Sekulić, D. P.: Fundamentals of Heat Exchanger Design, John Willey \& Sons, New Jersey, 2003. https://doi.org/10.1002/9780470172605

[3] Tarlet, D., Fan, Y., Roux, S., Luo, L.: Entropy generation analysis of a mini heat exchanger for heat transfer intensification, Experimental Thermal and Fluid Science, 53, pp. 119-26, 2014. https://doi.org/10.1016/j.expthermflusci.2013.11.016

[4] Manjunath, K., Kaushik. S.C.: The second law analysis of an unbalanced constructal heat exchanger, International Journal of Green Energy, 11(2), pp. 173-92, 2014. https://doi.org/10.1080/15435075.2013.772515

[5] Mahjoub, S., Salimpour, M.R., Shokouhmand, H., Bahrami, Z.: Entropy generation analysis in an evaporative air-cooled heat exchanger, Journal of Thermal Science and Technology, 9(1), pp. 1-12, 2014. https://doi.org/10.1299/jtst.2014jtst0004

[6] Leong, K.Y., Saidur, R., Khairulmaini, M., Michael, Z., Kamyar, A.: Heat transfer and entropy analysis of three different types of heat exchangers operated with nanofluids, International Communications in Heat and Mass Transfer, 39(6), pp. 838-43, 2012. https://doi.org/10.1016/j.icheatmasstransfer.2012.04.003

[7] Ye, H.Y., Lee, K.S.: Refrigerant circuitry design of fin-and-tube condenser based on entropy generation minimization, International Journal of Refrigeration, 35(5), pp. 1430-8, 2012. https://doi.org/10.1016/j.ijrefrig.2012.03.013 
[8] Giangaspero, G., Sciubba, E.: Application of the entropy generation minimization method to a solar heat exchanger: A pseudo-optimization design process based on the analysis of the local entropy generation maps, Energy, 58, pp. 52-65, 2013. https://doi.org/10.1016/j.energy.2013.01.069

[9] Xie, G., Song, Y., Asadi, M., Lorenzini, G.: Optimization of Pin-Fins for a Heat Exchanger by Entropy Generation Minimization and Constructal Law, Journal of Heat Transfer, 137(6), pp. 1-9, 2015. https://doi.org/10.1115/1.4029851

[10] Xu, M.T., Guo, J.F., Li, X.F.: Thermodynamic Analysis and Optimization Design of Heat Exchanger, In: Wang L., editor, Advances in Transport Phenomena. Storrs, Springer, pp. 63-167, 2014. https://doi.org/10.1007/978-3-319-01793-8_3

[11] Babaelahi, M., Sadri, S., Sayyaadi, H.: Multi-Objective Optimization of a Cross-Flow Plate Heat Exchanger Using Entropy Generation Minimization, Chemical Engineering \& Technology, 37(1), pp. 8794, 2014. https://doi.org/10.1002/ceat.201300411

[12] Li, M., Lai, A.C.K.: Thermodynamic optimization of ground heat exchangers with single U-tube by entropy generation minimization method, Energy Conversion and Management, 65, pp. 133-9, 2013. https://doi.org/10.1016/j.enconman.2012.07.013

[13] Galović, A.: Termodinamika II, Fakultet strojarstva i brodogradnje, Zagreb, 2013.

[14] Cengel, Y., A.: Heat Transfer, A Practical Approach, McGraw Hill, New York, 2003.

[15] Sekulić, D., P.: The Second Law Quality of Energy Transformation in a Heat Exchanger, 112 (2), pp. 295-300, 1990.

[16] Bošnjaković, F., Knoche, K., F.: Technische Thermodynamik, Teil II, Steinkopf, Darmstadt, 1997.

[17] Galović, A.: Analiza eksergijskih gubitaka istosmjernih i protusmjernih izmjenjivača topline, Strojarstvo 47, (5-6) str. 177-184 2005)

[18] Knoche, K. F., Henrich, F.: Exergy Losses and Energy Efficiency of Combined Power Cycles, Strojarstvo 44 (1-2), pp. 61-70, 2002.

[19] Gou, Z. Y., Chen, L.: Theoretical Analysis and Experimental Confirmation of the Uniformity Principle of Temperature Difference Field in Heat Exchanger, International Journal of Heat and Mass Transfer, 45 (10), pp. 2119 - 2127, 2002. https://doi.org/10.1016/S0017-9310(01)00297-6

[20] Hesselgraves, J. E.: Rationalization of Second Law Analysis of Heat Exchangers, International Journal of Heat and Mass Transfer, 43, pp. 4189 - 4204, 2000. https://doi.org/10.1016/S0017-9310(99)00364-6

[21] Nummedal, L., Kjelstrup, S.: Equipartition of Forces as a Lower Bound on the Entropy Production in Heat Exchange, International Journal of Heat and Mass Transfer, 44, pp. $2827-2833,2001$. https://doi.org/10.1016/S0017-9310(00)00321-5

[22] McGovern, J., Smith, B. P.: Rational Efficiency of a Heat Exchanger, Articles. Paper 27.

[23] Galović, A.: Non - dimensional Entropy Analysis of Condenser and/or Evaporator Heat Exchangers, International Journal of Heat Exchangers, Vol. V, pp. 337-346, 2004.

[24] Galović, A., Živić, M.,Can,A.:Energijska in eksergijska analiza sotočnih in protitočnih prenosnikov toplote z uporabo merilnih podatkov. // Strojniški vestnik, Journal of Mechanical Engineering. 53, 3; p.p.158-164, 2007.

[25] Singali, V., Aute, V., Radermacher, R.: Usefulness of Entropy Generation Minimization Through Heat Exchanger Modeling Tool, Refrigeration and Air Condition Conference, Paper 958, 2008.

Submitted: $\quad 28.6 .2017$

Accepted: $\quad 15.02 .2018$
Martina Rauch

Antun Galović

Nenad Ferdelji

Saša Mudrinić

Department of Thermodynamics, Thermal

and Process Engineering

Faculty of Mechanical Engineering and

Naval Architecture

University of Zagreb

Ivana Lučića 5, 10002 Zagreb, Croatia 